\title{
Breeding of wastewater treatment yeasts that accumulate high concentrations of phosphorus
}

\author{
Takashi Watanabe $\cdot$ Noriatsu Ozaki • \\ Kazuhiro Iwashita • Tsutomu Fujii • Haruyuki Iefuji
}

Received: 24 March 2008 /Revised: 1 May 2008 / Accepted: 3 May 2008 / Published online: 5 July 2008

(C) The Author(s) 2008

\begin{abstract}
Inorganic phosphate is an essential nutrient. In general, microorganisms take up phosphorus when the extracellular phosphorus concentration is low, but not when it is high. In Saccharomyces cerevisiae, the major phosphate transporters, such as Pho84p, and acid phosphatases (APases), such as Pho5p, are regulated in parallel by the phosphate signal transduction pathway ( $P H O$ pathway). We found that PHO mutants expressing PHOS4 and PHO5, even under high-P conditions, could take up phosphorus at twice the rate of the wild-type strain. The regulatory pathway for phosphorus accumulation in two wastewater treatment yeasts, Hansenula fabianii J640 and Hansenula anomala J224-1, was found to be similar to that in $S$. cerevisiae. We screened for mutants of these yeasts that constitutively expressed APase. Such mutants formed blue colonies on high phosphorus concentration agar plates containing 5-bromo-4-chloro-3-indolylphosphate (X-phosphate). We found four mutants of $H$. fabianii J640 and one mutant of H. anomala J224-1 that accumulated from 2.2 to 3.5 times more phosphorus than the parent strains. The growth rates and abilities to remove dissolved total nitrogen and dissolved organic carbon of the mutants were similar to those of the parent strains. In addition, the mutants removed
\end{abstract}

T. Watanabe $\cdot$ T. Fujii $\cdot$ H. Iefuji

Graduate School of Biosphere Science, Hiroshima University, 1-4-4 Kagamiyama, Higashihiroshima, Hiroshima 739-8527, Japan

T. Watanabe $\cdot$ K. Iwashita $\cdot$ T. Fujii $\cdot$ H. Iefuji $(\bowtie)$

National Research Institute of Brewing,

3-7-1 Kagamiyama, Higashihiroshima, Hiroshima 739-0046, Japan

e-mail: iefuji@nrib.go.jp

N. Ozaki

Graduate School of Engineering, Hiroshima University,

1-4-1 Kagamiyama, Higashihiroshima, Hiroshima 739-8527, Japan
95\% of dissolved total phosphorus from shochu wastewater, while the parent strain removed only $50 \%$.

Keywords Phosphorus - Wastewater treatment . Yeast $\cdot$ Polyphosphate accumulation $\cdot \mathrm{PHO}$ pathway

\section{Introduction}

Phosphorus is an essential nutrient for all organisms. It is widely used in the biosynthesis of cellular components, such as nucleic acids, phospholipids, and proteins. Therefore, phosphorus is added to plant fertilizers and animal feeds. However, phosphorus accumulation in the environment due to runoff from land treated with fertilizers and to the discharge of industrial and domestic waste, is a global problem which causes eutrophication of lakes, bays, and other surface waters. Considerable attention is therefore being paid to the removal of phosphorus from wastewaters (Kornberg et al. 1999). At the same time, it is anticipated that rock deposits high in phosphorus will be exhausted in the coming decades (Abelson 1999). Therefore, developing methods for removing and recycling phosphorus from wastewater would address both of these problems.

Two methods are currently used to remove and recycle phosphorus: chemical precipitation and biological removal. Phosphorus can be removed from sewage by precipitation using aluminum, calcium (to form hydroxyapatite compounds) and magnesium (to form magnesium ammonium phosphate (MAP) compounds, also called struvite; Durrant et al. 1999). Biological phosphorus removal (BPR) processes have been developed over the past 20 to 30 years. Conventional BPR processes are characterized by cycling between anaerobic and aerobic conditions (the A/O process; Seldark 1991) and are useful for sewage treatment. 
However, wastewater is a highly variable feedstock for these processes, so many treatment methods are required to deal with the large variation in wastewater characteristics. For example, wastewater with high concentrations of organics, such as shochu wastewater (filtered wastewater from shochu distilleries), and beer, beverage, and food industry wastewater, not only contains high concentrations of total phosphorus (T-P), but also have high chemical oxygen demand and high total nitrogen (T-N). It is therefore difficult to treat these various wastewaters using only the activated sludge method.

The upflow anaerobic sludge blanket (UASB) system is widely used for pretreatment of activated sludge (Seghezzo et al. 1998). Although the UASB system converts organic matter into methane effectively (Yamada et al. 2006), it is an anaerobic treatment and therefore cannot remove phosphorus. For this reason, a physicochemical phosphorus post-treatment removal process, such as MAP precipitation, is also required. Together UASB pretreatment and physicochemical post-treatment are expensive. Thus, it would be useful if these processes could be replaced with treatment with yeast strains that accumulate high concentrations of phosphorus. Such yeasts would not only treat organic matter, but also remove and allow recovery of phosphorus. Previously, the National Research Institute of Brewing (NRIB) of Japan developed a "wastewater treatment method using yeasts" (Yoshizawa 1978). This system removes large amounts of organic compounds, requires little space, and discharges little waste sludge but it was not designed for the removal of phosphorus. New phosphorusaccumulating strains are thus needed.

In general, the uptake of phosphorus by organisms is regulated by the extracellular phosphorus concentration. In Saccharomyces cerevisiae, phosphorus is taken up by the action of the PHO genes (Oshima 1997; Auesukaree et al. 2004), which are regulated by several phosphate-response genes. Two important $\mathrm{PHO}$ genes, $\mathrm{PHO} 44$ and $\mathrm{PHO}$, are regulated by the same transcriptional activators $P h o 2 p$ and Pho4p. Pho $84 p$ is a high affinity phosphate transporter located on the plasma membrane, and Pho5p is a repressible acid phosphatase which liberates phosphate from extracellular phosphoric compounds. When yeast strains encounter phosphate starvation conditions, the
PHO regulatory pathway is up-regulated to express the PHO81 and PHO5 and the yeast take up extracellular phosphorus (Urech et al. 1978; Ogawa et al. 1995; Kaffman et al. 1998). On the other hand, when phosphate concentrations are high, the $P H O$ regulatory pathway is downregulated (Oshima 1997).

Thus, PHO mutants in which Pho4p activates the expression of the phosphate transporter, Pho $84 \mathrm{p}$, and the acid phosphatase, Pho5p, even in high phosphate conditions, would be expected to effectively remove phosphorus from the culture solution. Furthermore, the PHO mutants that constitutively express $\mathrm{PHO} 44$ and have enhanced phosphorus removal ability would also be expected to constitutively express $\mathrm{PHO5}$, because $\mathrm{PHO} 44$ and $\mathrm{PHO} 5$ are regulated by the same transcriptional activators. The mutants that express acid phosphatase activity in high phosphate conditions would be easier to select by plate assay than the mutants that express phosphate transporter, because phosphatase activity can be identified by a color reaction on the plates. Thus, the goal was to find mutants that constitutively express phosphate transporter and acid phosphatase.

We thought this strategy would be useful to enhance phosphorus removal ability of wastewater treatment yeasts. We therefore attempted to select wastewater treatment yeast strains whose acid phosphatase activities are regulated by phosphorus concentration as they are in S. cerevisiae. Two yeast strains, Hansenula fabianii J640 (Kato et al. 1997) and Hansenula anomala J224-1 (Saito et al. 1990) were selected as candidates for creating mutants that efficiently remove phosphorus. Both strains were originally isolated in our laboratory as wastewater treatment yeasts. Here, we describe single mutants of each of these stains that accumulate high concentrations of phosphorus, and show that they would be useful for wastewater treatment.

\section{Materials and methods}

Strains

All the $S$. cerevisiae strains used (Table 1) were kindly provided by Dr. N. Ogawa at Stanford University. Waste-

Table 1 S. cerevisiae strains used in this study

\begin{tabular}{|c|c|c|}
\hline Strain & Relevant genotype & Reference \\
\hline S. cerevisiae NBW7 & MATa ade2 his3 leu2 trp1 ura3 pho3-1 & Ogawa and Oshima (1990) \\
\hline S. cerevisiae $\mathrm{NOF} 1^{\mathrm{a}}$ & MATa ade2 his3 leu2 trp1 ura3 pho3-1 PHO81 ${ }^{c}-1$ & Ogawa et al. (2000) \\
\hline S. cerevisiae $\mathrm{NBD} 82-1^{\mathrm{a}}$ & MATa ade2 his3 leu2 trp1 ura3 pho3-1 $\mathrm{PHO4}^{\mathrm{C}}-1$ & Ogawa and Oshima (1990) \\
\hline S. cerevisiae NBD4- $1^{\mathrm{a}}$ & MATa ade2 his3 leu2 trp1 ura3 pho3-1 $\triangle$ pho4::HIS3 & Ogawa and Oshima (1990) \\
\hline
\end{tabular}

${ }^{\mathrm{a}}$ These strains were derived from strain NBW7. 
water treatment yeast strains $H$. fabianii J640 (Kato et al. 1997), H. anomala J224-1 (Saito et al. 1990), Cryptococcus sp. S-2 (Iefuji et al. 1994a), and Geotrichum sp. M111 (Iefuji et al. 1994b) were isolated in our laboratory.

$H$. anomala J224-1 was isolated as a non-flocculating mutant from the flocculating yeast strain, H. anomala J224 (Saito et al. 1990).

\section{Media}

YM medium $(0.3 \%$ yeast extract, $0.3 \%$ malt extract, $0.5 \%$ peptone, $1 \%$ dextrose) and YPAD medium (1\% yeast extract, $2 \%$ peptone, $2 \%$ dextrose, $0.04 \%$ adenine) were used for pre-cultivation. SD medium ( $2 \%$ glucose, $0.227 \%$ L-asparagines monohydrate, $0.05 \% \mathrm{MgSO}_{4} \cdot 7 \mathrm{H}_{2} \mathrm{O}, 0.033 \%$ $\mathrm{CaCl}_{2} \cdot 2 \mathrm{H}_{2} \mathrm{O}, 0.1 \%$ vitamin mixture, $0.1 \%$ trace elements) was used for the acid phosphatase activity test. $\mathrm{KH}_{2} \mathrm{PO}_{4}$ was used to generate various phosphorus concentrations, and $\mathrm{KCl}$ was used to maintain a constant potassium concentration (Yoshida et al. 1989). Adenine and required amino acids were added to auxotrophic mutants. High PYPD medium (1\% yeast extract, $2 \%$ peptone, $2 \%$ dextrose, $0.4 \% \mathrm{KH}_{2} \mathrm{PO}_{4}$ ) was used for the phosphorus removal test and for screening mutants stained blue by the acid phosphatase hydrolysis of 5-bromo-4-chloro-indolylphosphate (X-phosphate; $50 \mathrm{mg} / \mathrm{l}$ in high P-YPD medium; Morohoshi et al. 2002). For auxotrophic mutants, adenine and required amino acids were added (high P-YPAD medium). Sweet potato shochu wastewater or barley shochu wastewater filtered through a miracloth (Wako) and diluted 1:1 with Milli-Q water was used for the wastewater treatment tests.

\section{Phosphorus removal test}

Yeast strains were pre-cultivated with shaking in $5 \mathrm{ml}$ of YPAD medium for $24 \mathrm{~h}$. The absorbance at $660 \mathrm{~nm}$ $\left(\mathrm{OD}_{660}\right)$ was measured in order to determine cell density. The cells were harvested, washed with sterilized $\mathrm{H}_{2} \mathrm{O}$ twice, then used to inoculate $50 \mathrm{ml}$ of high P-YPAD medium $(0.2$ $\mathrm{OD}_{660}$ ) in a $200-\mathrm{ml}$ flask. The cells were grown at $30^{\circ} \mathrm{C}$, $120 \mathrm{rpm} ; 5 \mathrm{ml}$ aliquots were harvested at $0,12,24$, and $36 \mathrm{~h}$, the $\mathrm{OD}_{660}$ was determined, the cells were centrifuged at 3,500 rpm for $10 \mathrm{~min}$, and the dissolved total phosphorus (DTP) in the supernatant was determined using standard methods (APHA et al. 1998).

Acid phosphatase activity test

Acid phosphatase activities at low and high phosphorus concentrations in the medium were tested using a plate assay (Dorn 1965). Yeast strains were cultivated in low and high phosphorus concentration SD medium for 1 or 2 days.
Then, $100 \mathrm{ml}$ of stain solution $(0.1 \mathrm{M}$ acetic acid buffer (pH 4.0), $50 \mathrm{mg} \alpha$-naphthyl calcium phosphate, $500 \mathrm{mg}$ Fast Blue B Salt) and $100 \mathrm{ml}$ of $3 \%$ heated agar solution were mixed and stratified on cultivation plates. After 0.5 to $1 \mathrm{~h}$, yeast strains secreting acid phosphatase were stained red.

\section{Mutation method}

Yeast strains were cultivated in $5 \mathrm{ml}$ of YM medium with shaking for $24 \mathrm{~h}$. Culture $(250 \mu \mathrm{l}), 4.6 \mathrm{ml}$ of $0.2 \mathrm{M}$ phosphoric acid buffer ( $\mathrm{pH} 8.0$ ), and $150 \mu \mathrm{l}$ of ethylmethanesulfonate (EMS: mutagenesis agent) were mixed in test tubes and the test tubes were shaken gently for $1 \mathrm{~h}$ at $30^{\circ} \mathrm{C}$. Hydrosulfite sodium solution $(6 \%)$ was added to stop EMS-induced mutation after $10 \mathrm{~min}$ (Lindegren et al. 1965). Following dilution with $67 \mathrm{mM}$ phosphoric acid buffer by 50 times, the diluted culture was spread on high P-YPD plates containing X-phosphate. Following overnight cultivation, about 1,000 colonies were apparent on the plates.

\section{DAPI fluorescence}

Polyphosphate granules in the cell were detected by $4^{\prime}, 6^{\prime}-$ diamidino-2-phenylindole (DAPI) fluorescence (Allan and Miller 1980; Morohoshi et al. 2002). Yeast strains were cultivated with shaking in $5 \mathrm{ml}$ of YPD medium for $24 \mathrm{~h}$. One milliliter of the culture was harvested and washed with sterilized $\mathrm{H}_{2} \mathrm{O}$ twice. The cell pellets were resuspended in $100 \mu \mathrm{l}$ of $0.05 \%$ DAPI solution. When excited with UV light, nuclei fluoresces blue, and polyphosphate fluoresces yellow. The samples were observed by fluorescent microscopy.

\section{Elution of phosphorus from yeast cells}

Yeast strains were cultivated with shaking in $5 \mathrm{ml}$ of YPD medium for $24 \mathrm{~h}$. The cells $\left(\mathrm{OD}_{660} \times\right.$ culture fluid $\left.(\mathrm{ml})=12\right)$ were harvested and washed with sterilized $\mathrm{H}_{2} \mathrm{O}$ twice. The cells pellets were resuspended in $50 \mathrm{ml}$ of $0.1 \mathrm{mM}$ Tris$\mathrm{HCl}$ buffer $(\mathrm{pH} 8.0)$ and incubated at $70^{\circ} \mathrm{C}$ for $1 \mathrm{~h}$ (Kuroda et al. 2002; Takiguchi et al. 2007). After incubation, the samples were centrifuged for $3 \mathrm{~min}$ at $15,000 \mathrm{rpm}$. The concentration of inorganic phosphate $\left(\mathrm{PO}_{4}-\mathrm{P}\right)$, poly-phosphate (Poly-P), and total phosphate (T-P) eluted in the supernatants was determined. $\mathrm{PO}_{4}-\mathrm{P}$ and T-P were assayed by standard methods, and Poly-P was determined by hydrolysis in $1 \mathrm{~N} \mathrm{HCl}$ at $100^{\circ} \mathrm{C}$ for 7 min (Kuroda et al. 2002).

Wastewater treatment with yeasts on a flask scale

Yeast strains were pre-cultivated with shaking in $5 \mathrm{ml}$ of YM medium for $24 \mathrm{~h}$. The cells were harvested, washed with 
sterilized $\mathrm{H}_{2} \mathrm{O}$ twice, inoculated into $50 \mathrm{ml}$ of sweet potato shoch $u$ wastewater or barley shoch $u$ wastewater $\left(0.2 \mathrm{OD}_{660}\right)$ in $200 \mathrm{ml}$ flasks, and grown at $30^{\circ} \mathrm{C}$ with shaking at $120 \mathrm{rpm}$. Aliquots of the culture $(1 \mathrm{ml})$ were removed after 0 , 12,24 , or $36 \mathrm{~h}$, the $\mathrm{OD}_{660}$ was determined, and the samples were centrifuged at 3,500 rpm for $10 \mathrm{~min}$; the $\mathrm{pH}$, dissolved total phosphorus, dissolved total nitrogen (DTN), and dissolved organic carbon (DOC) levels in the supernatants were determined using standard methods (APHA et al. 1998).

\section{Results}

Phosphorus removal by the model yeast, $S$. cerevisiae

We first tested our strategy for enhancing phosphorus removal with $\mathrm{PHO}$ regulatory mutants of $S$. cerevisiae. Figure 1 shows growth curves for these cells $\left(\mathrm{OD}_{660}\right.$ :

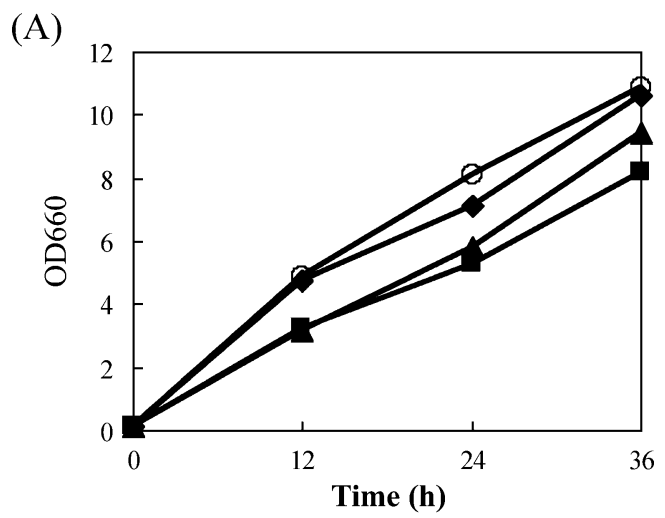

(B)

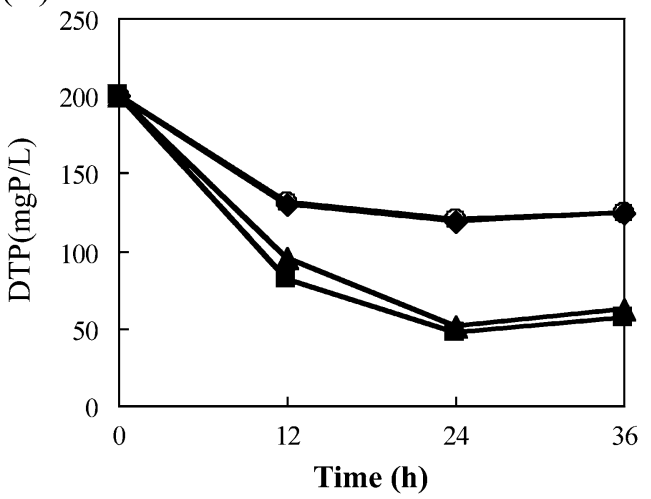

Fig. 1 Growth of the yeast strains (a) and the concentration of DTP left in the media (b) after $36 \mathrm{~h}$ of incubation. The wild-type, NBW7 (filled diamond), NOF1 (filled square), NBD82-1 (filled triangle), and NBD4-1 (empty circle) strains were incubated in $5 \mathrm{ml}$ of YPAD medium with shaking for $24 \mathrm{~h}$. The cells were harvested, washed with sterilized $\mathrm{H}_{2} \mathrm{O}$ twice, and then inoculated into $50 \mathrm{ml}$ of high P-YPAD medium $\left(\mathrm{OD}_{660}=0.2\right)$ in a $200-\mathrm{ml}$ flask and incubated at $30^{\circ} \mathrm{C}$ with shaking at $120 \mathrm{rpm}$. The culture $(5 \mathrm{ml})$ was harvested at each time point $(0,12,24$, and $36 \mathrm{~h})$, the $\mathrm{OD}_{660}$ assayed, and then the samples were centrifuged at $3,500 \mathrm{rpm}$ for $10 \mathrm{~min}$. DTP of the supernatants were determined using standard methods
Fig. 1a) and the concentration of residual phosphorus in high-P YPAD medium (DTP: Fig. 1b).

NOF1 and NBD82-1, whose $P H O$ regulation pathways were up-regulated, grew more slowly than the two other strains (Fig. 1a). The wild-type strain NBW7 and the $P H O$ down-regulated mutant NBD4-1 could remove only $35 \%$ of the soluble phosphate after $24 \mathrm{~h}$, apparently because their PHO regulation pathways were down-regulated. However, the mutants NOF1 and NBD82-1 could remove about $75 \%$ of the DTP from the cultivation medium after $24 \mathrm{~h}$.

Selection of candidates from wastewater treatment yeasts

When the phosphorus concentration of the medium was low, all but NBD4-1 were stained red, showing that they exhibit significant acid phosphatase activity (Table 2). When the phosphorus concentration of the medium was high, NOF1 and NBD82-1 showed activity, whereas NBW7 and NBD4-1 did not. H. fabianii J640 and $H$. anomala J224-1 stained red in low-P medium but were not stained in high-P medium, indicating that the acid phosphatase activity of these two strains is affected by phosphorus concentration. Cryptococcus sp. S-2 was stained red in both low-P and high-P medium, showing that its acid phosphatase is likely activated constitutively. Geotrichum sp. M111 was not stained in either low-P or high-P medium.

Based on these results, we selected H. fabianii J640 and H. anomala J224-1 as candidates for improving their phosphorus removal capability.

Screening of constitutive acid phosphatase expression mutants

We first selected constitutive acid phosphatase expression mutants, which formed blue colonies on high P-YPD plates

Table 2 Acid phosphatase activity of the yeast strains in media with low and high phosphorus concentration (6 and $163 \mathrm{mg} / \mathrm{l}$ total phosphorus, respectively)

\begin{tabular}{lll}
\hline Strain & \multicolumn{2}{l}{ Acid phosphate activity } \\
\cline { 2 - 3 } & Low-P medium & High-P medium \\
\hline S. cerevisiae NBW7 & + & - \\
S. cerevisiae NOF1 & + & + \\
S. cerevisiae NBD82-1 & + & + \\
S. cerevisiae NBD4-1 & - & - \\
H. fabianii J640 & + & - \\
H. anomala J224-1 & + & - \\
Cryptococcus sp. S-2 & + & + \\
Geotrichum sp. M111 & - & - \\
\hline
\end{tabular}

+ Detected acid phosphatase activity, - not detected acid phosphatase activity 
Table 3 The growth and amount of phosphate removal per unit $\mathrm{OD}_{660}$ of the yeast strains

\begin{tabular}{lccc}
\hline Strain & $\mathrm{OD}_{660}$ & Residual P (mg P/l) & Removal P per OD $660_{\left(\mathrm{mg} \mathrm{P} / 1 \cdot \mathrm{OD}_{660}\right)}$ \\
\hline H. fabianii J640 (wild strain) & 32.1 & 62.7 & 4.3 \\
H. fabianii J640 PFW1 & 17.7 & 59.2 & 8.4 \\
H. fabianii J640 PFW2 & 17.2 & 46.2 & 9.0 \\
H. fabianii J640 PFW3 & 12.0 & 60.5 & 11.7 \\
H. fabianii J640 PFW4 & 23.9 & 23.4 & 7.4 \\
H. anomala J224-1 (wild strain) & 24.3 & 69.4 & 4.8 \\
H. anomala J224-1 PAW1 & 17.1 & 58.4 & 8.4 \\
\hline
\end{tabular}

Each strain was incubated in $5 \mathrm{ml}$ of YM medium with shaking for $48 \mathrm{~h}$. The cells were harvested, inoculated into $50 \mathrm{ml}$ of high P-YPAD medium $\left(\mathrm{OD}_{660}=0.2\right)$ in a $200-\mathrm{ml}$ flask, and grown at $30^{\circ} \mathrm{C}$ with shaking at $120 \mathrm{rpm}$ for $24 \mathrm{~h}$. The growth was measured by $\mathrm{OD}_{660}$, and residual phosphorus was measured in the cultivation media. Removal of phosphorus per $\mathrm{OD}_{660}$ was calculated removal phosphorus, phosphorus concentration of initial media make allowance after cultivation media, divided by $\mathrm{OD}_{660}\left((\right.$ initial $\mathrm{P}-$ residual $\left.\mathrm{P}) / \mathrm{OD}_{660}\right)$.

containing X-phosphate. The mutagenized samples of $H$. fabianii $\mathrm{J} 640$ and $H$. anomala $\mathrm{J} 224-1$ were spread on about 600 plates, and each plate yielded about 1,000 colonies (total number of colonies: 0.6 million). Sixty-six candidates from H. fabianii $\mathrm{J} 640$ and 322 candidates from H. anomala $\mathrm{J} 224-1$ were isolated as blue colonies, indicating that these candidates were constitutive acid phosphatase expression mutants.

Selection of mutants capable of removing high levels of phosphorus

The mutants constitutively expressing acid phosphatase, and the parental strains, were each cultivated in $5 \mathrm{ml}$ of high-P YPD medium for $24 \mathrm{~h}$ at $30^{\circ} \mathrm{C}$ with shaking, and the residual phosphorus concentration in the media was assayed. Ten mutants were isolated from H. fabianii J640 and 22 mutants were isolated from $H$. anomala J224-1 which could remove more phosphorus than the parent strains.

These selected mutants and their parent strains were precultivated in YM medium and then cultured in $50 \mathrm{ml}$ of high P-YPAD medium $\left(0.2 \mathrm{OD}_{660}\right)$ for $24 \mathrm{~h}$, after which the
$\mathrm{OD}_{660}$ and residual phosphorus concentrations in the media were assayed. Four mutants from H. fabianii J640 (PFW1, PFW2, PFW3, and PFW4) and one mutant from $H$. anomala J224-1 (PAW1) were isolated. These mutants remove phosphorus concentrations 1.7 to 2.7 times higher than the parent strains (Table 3).

\section{Accumulation of phosphorus and polyphosphate}

Following staining with DAPI, polyphosphate granules in the vacuoles of $H$. fabianii $\mathrm{J} 640$ and $H$. anomala J224-1 were observed by fluorescence microscopy (data not shown), indicating that these strains accumulate phosphorus as polyphosphate in the vacuoles. The amount of total phosphorus per mutant cell was 2.2-3.5 times larger than that in the parent strains (Table 4). In addition, the amount of polyphosphate eluted from the mutants was 3-5 times higher than that from the parent stains.

Of the four mutants isolated from H. fabianii J640, PFW4 grew the fastest and removed the largest amount of phosphorus, so this mutant was used for further experiments.

Table 4 The content of phosphorus in the yeast strains

\begin{tabular}{|c|c|c|c|c|}
\hline Strains & $\begin{array}{l}\mathrm{PO}_{4} \text { of elution } \\
\left(\mathrm{mg} \mathrm{P} / \mathrm{l} \cdot \mathrm{OD}_{660}\right)\end{array}$ & $\begin{array}{l}\text { Poly-P of elution }{ }^{\mathrm{a}} \\
\left(\mathrm{mg} \mathrm{P} / 1 \cdot \mathrm{OD}_{660}\right)\end{array}$ & $\begin{array}{l}\text { T-P of elution }{ }^{\mathrm{a}} \\
\left(\mathrm{mg} \mathrm{P} / 1 \cdot \mathrm{OD}_{660}\right)\end{array}$ & $\begin{array}{l}\text { T-P of cells }{ }^{\mathrm{b}} \\
\left(\mathrm{mg} \mathrm{P} / 1 \cdot \mathrm{OD}_{660}\right)\end{array}$ \\
\hline H. fabianii J640 (wild strain) & 0.35 & 0.59 & 1.12 & 1.89 \\
\hline H. fabianii J640 PFW1 & 0.64 & 2.88 & 3.50 & 6.59 \\
\hline H. fabianii J640 PFW2 & 0.54 & 2.76 & 3.32 & 5.29 \\
\hline H. fabianii J640 PFW3 & 0.49 & 3.16 & 3.67 & 6.46 \\
\hline H. fabianii J640 PFW4 & 0.71 & 2.33 & 2.98 & 4.71 \\
\hline H. anomala J224-1 (wild strain) & 0.55 & 1.30 & 2.09 & 3.86 \\
\hline H. anomala J224-1 PAW1 & 0.38 & 4.03 & 4.60 & 8.34 \\
\hline
\end{tabular}

Each strain was incubated in $5 \mathrm{ml}$ of high-P YPD medium with shaking for $24 \mathrm{~h}$.

${ }^{a}$ Elution of yeast cells following heating at $70^{\circ} \mathrm{C}$ for $1 \mathrm{~h} . \mathrm{PO}_{4}-\mathrm{P}$ and T-P were assayed by standard methods; poly-P was hydrolyzed to $\mathrm{PO}_{4}-\mathrm{P}$ by heating at $100^{\circ} \mathrm{C}$ for 7 min with $1 \mathrm{~N} \mathrm{HCl}$, then assayed by standard methods.

${ }^{\mathrm{b}}$ Total phosphorus content of the yeast cells was assayed by standard methods. 
Removal of phosphorus from shochu wastewater

Cell growth for $H$. fabianii J640 and the mutant PFW4 (Fig. 2a) and H. anomala J224-1 and the mutant PAW1 (Fig. 2b) in sweet potato shochu wastewater were almost same. Changes in DTN, DOC, and pH were also almost the same (data not shown). On the other hand, the mutants (PFW4 and PAW1) could remove about 95\% of DTP from the wastewater (36 h: Fig. 2c,d), while the parent strains removed only about half. Similar results were obtained with barley shochu wastewater (data not shown).

Figure 3 shows the concentration of inorganic phosphate $\left(\mathrm{PO}_{4}-\mathrm{P}\right)$ and other phosphorus compounds in sweet potato and barley shochu wastewater following cultivation of each yeast strain for $36 \mathrm{~h}$. Sweet potato and barley shochu wastewater contained $30 \%$ and $45 \%$ organic phosphorus compounds of DTP, respectively. In contrast, the parent strains removed only $50 \%$ to $70 \%$ of $\mathrm{PO}_{4}-\mathrm{P}$ and $30 \%$ to $50 \%$ of organic phosphorus compounds. The mutants efficiently removed not only inorganic phosphate $\left(\mathrm{PO}_{4}-\mathrm{P}\right)$ but also organic phosphorus compounds.

The ratio of $\mathrm{C} / \mathrm{N}$ removal was almost the same between parents and mutants (around 100:5.4 6.5), but the ratio of
$\mathrm{C} / \mathrm{P}$ removal by the mutants (around 100: 2.8 3.3) was twice that of the parent strain (around 100: 1.5 1.8) in each shochu wastewater (Tables 5).

\section{Discussion}

In this study, we bred two wastewater treatment yeasts, $H$. fabianii J640 PFW4 and $H$. anomala J224-1 PAW1, that accumulated 2.2 to 3.5 times more phosphorus than the parent strains.

In $S$. cerevisiae, the $P H O$ regulatory pathway senses phosphorus concentration signals and regulates the uptake of phosphorus (Oshima 1997; Auesukaree et al. 2004). The major phosphate transporters, such as Pho84p, and acid phosphatases, such as Pho5p, are regulated in parallel by the $P H O$ regulatory pathway. In this study, we showed that $\mathrm{PHO}$ mutants that constitutively express $\mathrm{PHO} 84$ and $\mathrm{PHO} 5$ could take up phosphorus at twice the rate of the wild-type strain. We also showed that in two wastewater treatment yeast strains, $H$. fabianii J640 and $H$. anomala J224-1, acid phosphatase activities were regulated by the extracellular phosphorus concentration. We believe that some mutation
Fig. 2 Growth $(\mathbf{a}, \mathbf{b})$ and DTP uptake (c, d) of wild-type strains and mutants. Wild-type strain $H$. fabianii J640 (filled square) its mutant PFW4 (empty square) and wild-type strain $H$. anomala J224-1 (filled triangle) and its mutant PAW1 (empty circle) were incubated in $5 \mathrm{ml}$ of $\mathrm{YM}$ medium with shaking for $48 \mathrm{~h}$. The cells were harvested and inoculated in $50 \mathrm{ml}$ of wastewater $\left(\mathrm{OD}_{660}=0.2\right)$ in a $200-\mathrm{ml}$ flask and grown at $30^{\circ} \mathrm{C}$ with shaking at $120 \mathrm{rpm}$
(A)

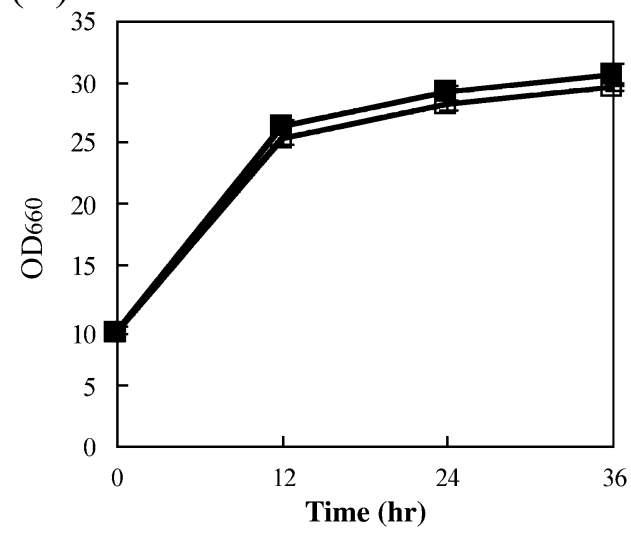

(C)

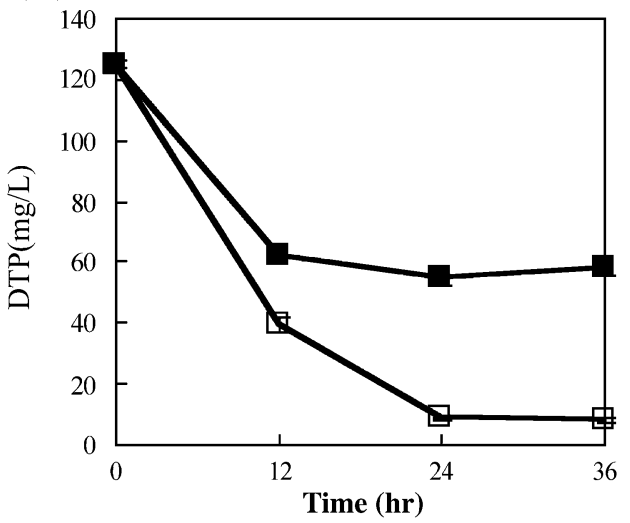

(B)

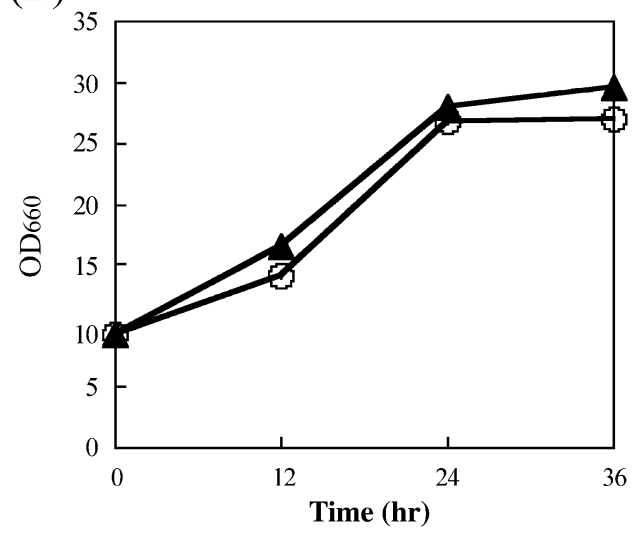

(D)

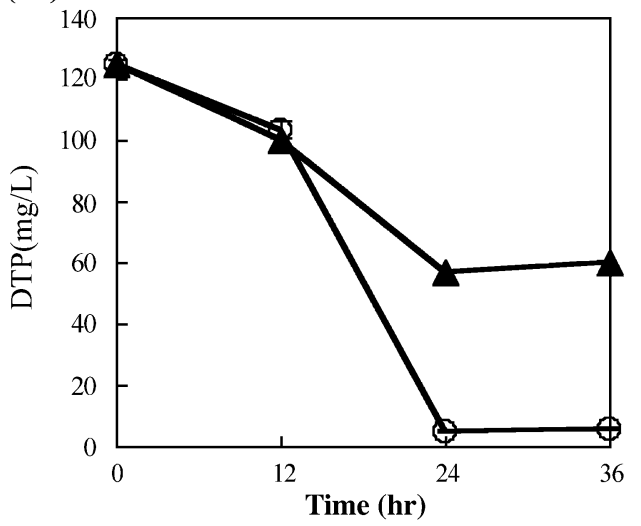


in the regulatory pathways of $H$. fabianii J640 PFW4 and H. anomala J224-1 PAW1 causes phosphate transporters and acid phosphatase to be constitutively expressed, leading to enhanced uptake and accumulate of phosphorus.

In bacteria, the pho regulon regulates the uptake of phosphorus (Amemura et al. 1985). Kato et al. (1993) created recombinant Escherichia coli that overexpressed genes encoding polyphosphate kinase $(p p k)$ and the phosphate-specific transport system (pstSCAB).This strain accumulated high levels of polyphosphate with phosphorus accounting for $16 \%$ of its dry weight. However, the recombinant strain grew too slowly to be practical for treating wastewater.

The high-P accumulating yeasts $H$. fabianii J640 PFW4 and H. anomala J224-1 PAW1 efficiently removed not only
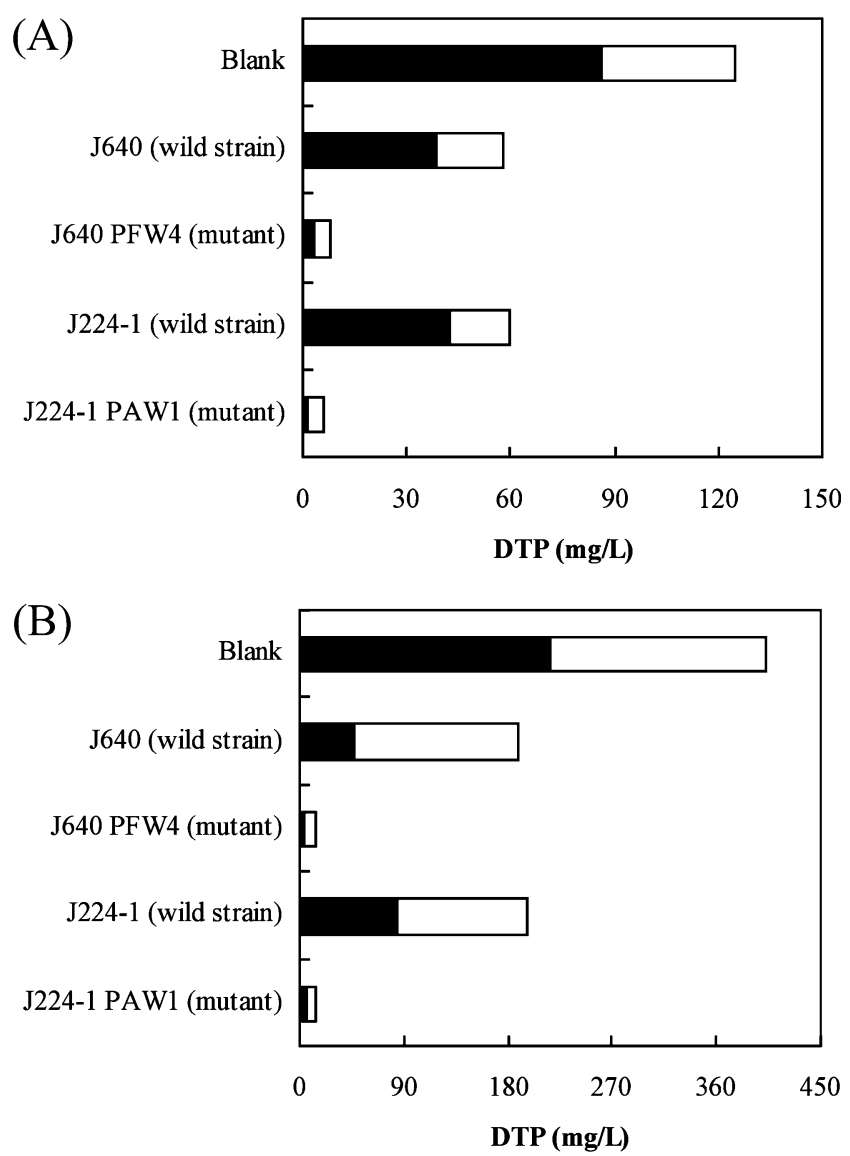

Fig. 3 The concentration of phosphorus and its composition of cultivated wastewater (a sweet potato shochu wastewater, b barley shochu wastewater). Each strain was inoculated in $50 \mathrm{ml}$ of wastewater $\left(\mathrm{OD}_{660}=0.2\right)$ in a $200-\mathrm{ml}$ flask and grown at $30^{\circ} \mathrm{C}$ with shaking at $120 \mathrm{rpm}$ for $36 \mathrm{~h}$. $\mathrm{PO}_{4}-\mathrm{P}$ (black bars) and organic phosphorus compounds (white bars) were assayed by standard methods
Table 5 Ratio of the removal of carbon, nitrogen, and phosphorus $(\mathrm{C} /$ $\mathrm{N} / \mathrm{P}$ ) in cultivated and cultivated barely sweet potato shochu wastewater

\begin{tabular}{llll}
\hline Strains & $\mathrm{C}$ & $\mathrm{N}$ & $\mathrm{P}$ \\
\hline \multicolumn{2}{l}{ Cultivated sweet potato shochu wastewater } & & \\
H. fabianii J640 (wild strain) & 100 & 5.7 & 1.6 \\
H. fabianii J640 PFW4 & 100 & 5.4 & 2.8 \\
H. anomala J224-1 (wild strain) & 100 & 5.8 & 1.5 \\
H. anomala J224-1 PAW1 & 100 & 5.8 & 2.9 \\
Cultivated barely shochu wastewater & & & \\
H. fabianii J640 (wild strain) & 100 & 6.0 & 1.8 \\
H. fabianii J640 PFW4 & 100 & 6.3 & 3.3 \\
H. anomala J224-1 (wild strain) & 100 & 6.5 & 1.8 \\
H. anomala J224-1 PAW1 & 100 & 5.8 & 3.3 \\
\hline
\end{tabular}

inorganic phosphate, but also phosphorus compounds (Fig. 3). Phosphorus is imported into yeast cells through the high/low affinity phosphate transporter as inorganic phosphate. In the process of breeding high-P accumulating yeasts, we selected mutants that, unlike their parent strains, secreted acid phosphatases in high phosphorus medium. The rationale was that the secreted acid phosphatase would hydrolyze phosphorus compounds to inorganic phosphate, which would be easier for the yeasts to take up.

Because the sludge of $H$. fabianii J640 PFW4 and $H$. anomala J224-1 PAW1 accumulate high level phosphorus (Table 4), it would be utilized for producing phosphorous and nitrogenous animal feed and/or plant fertilizers. In addition, the sludge of these strains accumulated phosphorus as polyphosphate granules. By heating the sludge to $70^{\circ} \mathrm{C}$, the phosphorus was easily eluted to the liquid phase from the cells (Kuroda et al. 2002). Phosphate and polyphosphate can be precipitated from this solution adding $\mathrm{CaCl}_{2}$ (Kuroda et al. 2002). The recovered phosphorus has a high degree of purity and would be useful in various industrial applications.

Acknowledgments We thank Dr. N. Ogawa at Stanford University for generously providing $S$. cerevisiae NBW7 and its $\mathrm{PHO}$ mutants, and Dr. A. Kuroda at Hiroshima University for advice regarding the use of X-phosphate for screening constitutive acid phosphatase expression mutants, and for the heating methodology for releasing phosphorus.

This work was supported by the Ministry of the Environment of Japan.

Open Access This article is distributed under the terms of the Creative Commons Attribution Noncommercial License which permits any noncommercial use, distribution, and reproduction in any medium, provided the original author(s) and source are credited. 


\section{References}

Abelson PH (1999) A potential phosphate crisis. Science 283:2015

Allan RA, Miller JJ (1980) Influence of $S$-adenosylmethionine on DAPI-induced florescence of polyphosphate in the yeast vacuole. Can J Microbiol 26:912-920

Amemura M, Makino K, Shinagawa H, Kobayashi A, Nakata A (1985) Nucleotide sequence of the genes involved in phosphate transport and regulation of the phosphate regulon in Escherichia coli. J Mol Biol 184:241-250

APHA, AWWA, WEF (1998) Standard methods for the examination of water and wastewater, 20th edn. American Public Health Association, Washington, DC

Auesukaree C, Homma T, Tochio H, Shirakawa M, Kaneko Y, Harashima S (2004) Intracellular phosphate serves as a signal for regulation of the PHO pathway in Saccharomyces cerevisiae. J Biol Chem 279:17289-17294

Dorn G (1965) Genetic analysis of the phosphatases in Aspergillus nidulans. Genet Res 10:13-26

Durrant AE, Scrimshaw MD, Stratful I, Lester JN (1999) Review of the feasibility of recovering phosphate from wastewater for use as a raw material by phosphate industry. Environ Technol 20:411-416

Iefuji H, Iimura Y, Obata T (1994a) Isolation and characterization of a yeast Cryptococcus sp. S-2 that produces raw starch-digesting aamylase, xylanase, and polygalacturonase. Biosci Biotech Biochem 58:2261-2262

Iefuji H, Kishi J, Iimura Y, Obata T (1994b) Isolation of a yeast strain that accelerates aggregation of cellulose fiber and its use in treatment of wastewater from sweet-potato shochu distilleries. Nippon Nougeikagaku Kaishi 68:33-40 (in Japanese)

Kaffman A, Rank NM, O'Neill EM, Huang LS, O'Shea EK (1998) The receptor Msn5 exports the phosphorylated transcription factor Pho4 out of nucleus. Nature 396:482-486

Kato J, Yamada K, Muramatsu A, Hardoyo, Ohtake H (1993) Genetic improvement of Escherichia coli for enhanced biological removal of phosphate from wastewater. Appl Environ Microbiol 59:3744-3749

Kato M, Iefuji H, Miyake K, Iimura Y (1997) Transformation system for a wastewater treatment yeast, Hansenula fabianii J640: isolation of the orotidine-5'-phosphate decarboxylase gene (URA3) and uracil auxotrophic mutants. Appl Environ Microbiol 48:621-625

Kornberg A, Rao NN, Ault-Riche D (1999) Inorganic phosphate: a molecular of many functions. Annu Rev Biochem 68:89-125

Kuroda A, Takiguchi N, Gotanda T, Nomura K, Kato J, Ikeda T, Ohtake H (2002) A simple method to release polyphosphate from activated sludge for phosphorus reuse and recycling. Biotech Bioeng 78:333-338

Lindegren G, Hwang YL, Oshima Y, Lindegren CC (1965) Genetical mutants induced by ethylmethanesulfonate in Saccharomyces. Can J Genet Cytol 7:491-499

Morohoshi T, Maruo T, Shirai Y, Kato J, Ikeda T, Takiguchi N, Ohtake H, Kuroda A (2002) Accumulation of inorganic phosphate in phoU mutants of Escherichia coli and Synechocystis sp. strain PCC6803. Appl Environ Microbiol 68:4107-4110

Ogawa N, Noguchi K, Swai H, Yamashita Y, Yompakudee C, Oshima Y (1995) Functional domains of Pho81p, an inhibitor of the Pho85p protein kinase, in the transduction pathway for Pi signals in Saccharomyces cerevisiae. Mol Cell Biol 15:997-1004

Ogawa N, Oshima Y (1990) Functional domains of a positive regulatory protein, $\mathrm{PHO} 4$, for transcriptional control of the phosphatase regulon in Saccharomyces cerevisiae. Mol Cell Biol 10:2224-2236

Ogawa N, Derisi J, Brown PO (2000) New components of a system for phosphate accumulation and polyphosphate metabolism in Saccharomyces cerevisiae revealed by genomic expression analysis. Mol Biol Cell 11:4309-4321

Oshima Y (1997) The phosphate system in Saccharomyces cerevisiae. Genes \& Genet Syst 72:323-334

Saito K, Sato S, Shimoi H, Iefuji H, Tadenuma M (1990) Flocculation mechanism of Hansenula anomala J224. Agric Biol Chem $54: 1425-1432$

Seghezzo L, Zeeman G, van Lier JB, Hamelers HVM, Lettinga G (1998) A review: the anaerobic treatment of sewage in UASB and EGSB reactors. Bioresour Technol 65:175-190

Seldark RI (1991) Phosphorus and nitrogen removal from municipal wastewater, 2nd edn. Lewis, New York, NY

Takiguchi N, Kishino M, Kuroda A, Kato J, Ohtake H (2007) Effect of mineral elements on phosphorus release from heated sewage sludge. Bioresour Technol 98:2533-2537

Urech K, Duerr M, Boller TH, Wiemken A (1978) Localization of polyphosphate in vacuoles of Saccharomyces cerevisiae. Arch Microbiol 116:275-278

Yamada M, Yamaguchi M, Suzuki T, Ohashi A, Harada H (2006) Onsite treatment of high-strength alcohol distillery wastewater by a pilot-scale thermophilic multi-staged UASB (MS-UASB) reactor. Water Sci Technol 53:27-35

Yoshida K, Kuromitsu Z, Ogawa N, Oshima Y (1989) Mode of expression of the positive regulatory genes $\mathrm{PHO} 2$ and $\mathrm{PHO} 4$ of the phosphatase regulon in Saccharomyces cerevisiae. Mol Gen Gent 217:31-39

Yoshizawa K (1978) Treatment of waste-water discharged from sake brewery using yeast. J Ferment Technol 56:389-395 